\title{
Acral Amelanotic Melanoma
}

\section{Melanoma Amelanótico Acral}

\author{
Rita BOUCEIRO-MENDES $\triangle 1$, Luís SOARES-DE-ALMEIDA ${ }^{1,2}$ \\ Acta Med Port 2021 Jun;34(6):468-468 - https://doi.org/10.20344/amp.13044
}

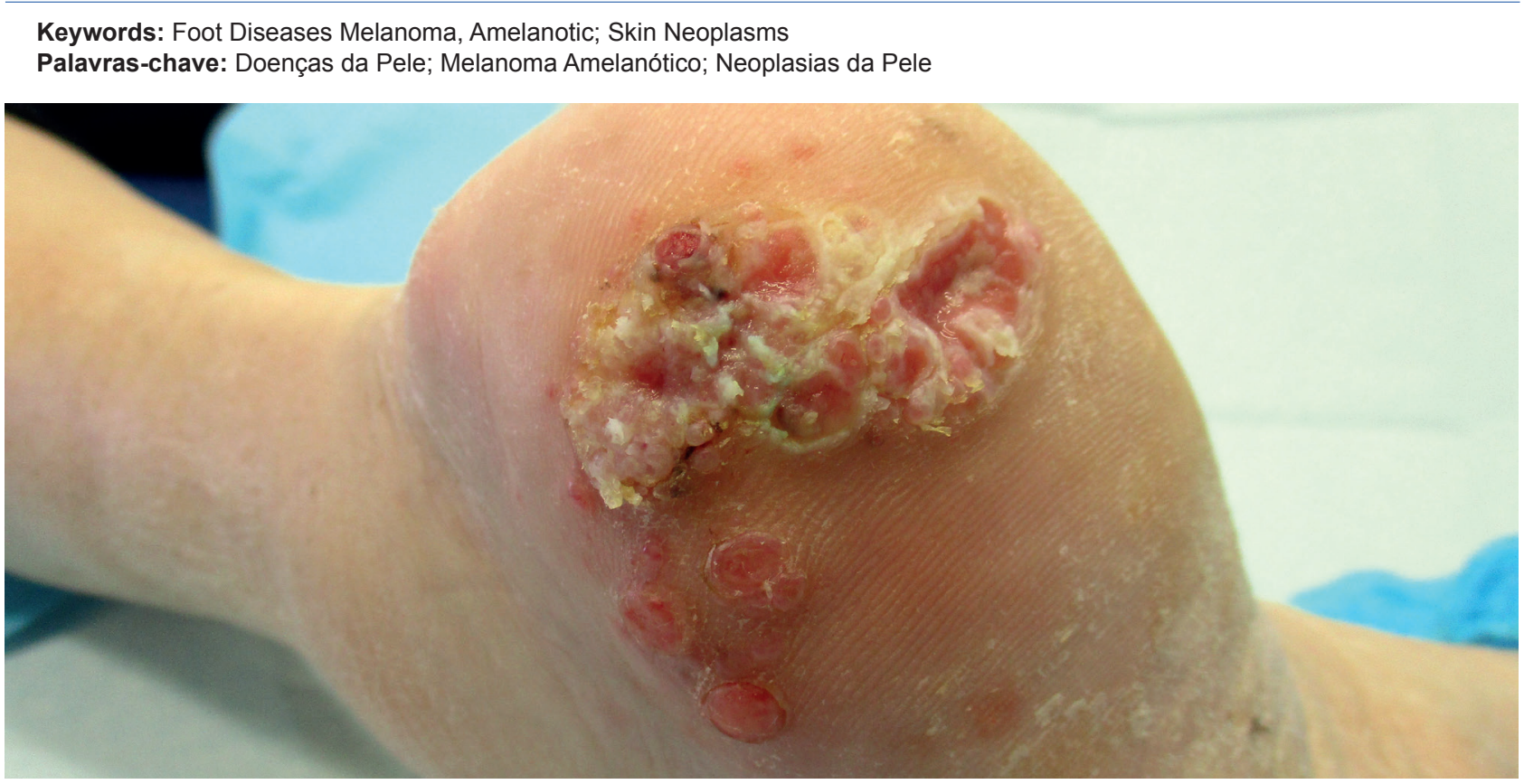

Figure 1 - Acral amelanotic melanoma

Acral melanomas are rare, ${ }^{1}$ representing $2 \%-3 \%$ of all melanomas. ${ }^{2}$ However, the fatality rate is higher because of delayed diagnosis. ${ }^{1-3}$ They are more common on weightbearing areas of the foot ${ }^{2,4,5}$ and are frequently amelanotic sometimes mimicking fungal infections, diabetic foot ulcers or even plantar warts. ${ }^{1-3}$

A 66-year-old woman was seen for a seven-month history of asymptomatic and ulcerated pink nodules, located on her left calcaneus. The lesions had developed spontaneously, and she was receiving wound care treatment for the last three months with no improvement. The histopathologi- cal examination revealed an acral lentiginous melanoma with a thickness (Breslow) of $6 \mathrm{~mm}$ extending into the subcutaneous tissue (Clark level V), which was managed with surgery and isolated limb perfusion (sentinel lymph node biopsy was positive with no other evidence of distant disease).

This case highlights the importance of considering melanoma in the differential diagnosis of non-healing ulcerated foot lesions. Surgery is the definitive treatment for earlystage disease while medical management is generally reserved for adjuvant treatment. ${ }^{2,3}$

PROTECTION OF HUMANS AND ANIMALS: The authors declare that the procedures were followed according to the regulations established by the Clinical Research and Ethics Committee and to the Helsinki Declaration of the World Medical Association. DATA CONFIDENTIALITY: The authors declare having followed the protocols in use at their working center regarding patients' data publication. INFORMED CONSENT: Obtained. CONFLICTS OF INTEREST: All authors report no conflict of interest. FUNDING SOURCES: The authors declare that there were no external sources of study for the performance of this article.

\section{REFERENCES}

1. Cozzani E, Gasparini G, Intersimone D, Cestari R, Cioni M, Parodi A. Amelanotic acral melanoma mimicking a plantar wart. JAAD Case Rep. 2019;5:4246 .

2. Cantwell P, Van Dam H. Acral amelanoticmelanoma mimicking a non-healing arterial ulcer. Case Rep Dermatol. 2019;11:77-81.

3. Muinonen-Martin AJ, O'Shea SJ, Newton-Bishop J. Amelanotic melanoma. BMJ. 2018;360:k826.

4. Costello CM, Pittelkow MR, Mangold AR. Acral melanoma and mechanical stress on the plantar surface of the foot. N Engl J Med. 2017;377:395-6.

5. Wee E, Wolfe R, McLean C, Kelly JW, Pan Y. Clinically amelanotic or hypomelanotic melanoma: anatomic distribution, risk factors, and survival. J Am Acad Dermatol. 2018;79:645-51.e4

1. Departamento de Dermatologia. Centro Hospitalar Universitário de Lisboa Norte. Lisboa. Portugal.

2. Instituto de Medicina Molecular. Faculdade de Medicina. Universidade de Lisboa. Lisboa. Portugal.

$\triangle$ Autor correspondente: Rita Bouceiro Mendes. rita.bouceiro.mendes@gmail.com

Recebido: 04 de novembro de 2019 - Aceite: 07 de fevereiro de 2020 - First published: 13 de abril de 2021 - Online issue published: 01 de junho de 2021 Copyright (C) Ordem dos Médicos 2021 